\title{
FINALITAS YESUS MENURUT KLAUSA "SESUNGGUHNYA AKULAH PINTU KE DOMBA-DOMBA ITU”: EKSEGESIS INJIL YOHANES 10:7
}

\author{
Sensius Amon Karlau \\ STT Arastamar Wamena \\ Email: sensiuskarlau07@gmail.com
}

\begin{abstract}
ABSTRAK
Klaim yang sering dilontarkan oleh pengikut Yesus mengenai finalitas-Nya sebagai satu-satunya Juruselamat terus ditentang oleh kelompok yang berspekulasi menolak pernyataan dimaksud seperti halnya kaum liberal dan konservatif yang membangun pemahaman secara subjektif. Hal ini berdampak pada upaya pertanggungjawaban iman yang semakin mengalami distorsi religiusitas iman pada masa lampau hingga saat ini. Artikel ini bertujuan mengetengahkan mengenai finalitas Yesus sebagaimana Ia kemukakan bagi kelompok yang menolak maupun juga kepada pengikut-Nya dalam upaya pemerkayaan pengajaran kristologi masa kini. Penulis menggunakan metode kualitatif dengan pendekatan eksegesis dengan teknik pengumpulan data yaitu telaah pustaka guna memahami makna "sesungguhnya Akulah Pintu ke domba-domba itu" menurut Injil Yohanes 10:7. Dengan demikian maka dapat disimpulkan bahwa secara terbuka Yesus menyampaikan bagi para pendengar-Nya agar dapat mengakui finalitas-Nya sebagai satu-satunya "Jalan masuk" melalui "Sang Pintu" yang sekaligus adalah "Sang Gembala yang baik" dan tidak ada lagi sarana lain selain diri-Nya. Dan pemahaman kristologis tidak dapat dilakukan berdasarkan asumsi subjektivitas manusia melainkan berdasarkan pernyataan Yesus sendiri sebagaimana dinarasikan "sesungguhnya Akulah Pintu ke domba-domba itu".
\end{abstract}

Kata Kunci: Finalitas Yesus; Gembala; Eksegesis; Pintu; Domba.

\begin{abstract}
The frequent claims made by followers of Jesus regarding His finality as the only Savior continue to be challenged by groups who speculate against such claims as do liberals and conservatives who build on subjective understanding. This has an impact on efforts to account for faith which have increasingly experienced distortion of the religiosity of faith in the past to the present. This article aims to present the finality of Jesus, as He spoke of both to groups who reject it as well as to His followers in an effort to enrich the teachings of modern Christology. The author uses qualitative methods with an exegetical approach with data collection techniques, namely reviewing the literature in order to understand the meaning of "actually I am the door to the sheep" according to the Gospel of John 10: 7. Thus, it can be concluded that Jesus openly conveyed to His listeners in order to acknowledge His finality as the only "Way of Entry" through "The Door" which is also "the Good Shepherd" and there is no other means besides. Himself. And christological understanding cannot be made based on the assumption of
\end{abstract}


human subjectivity but based on the statement of Jesus himself as narrated "in fact I am the Door to the sheep".

Keywords: Jesus' finality; Shepherd; Exegesis, the Door; Sheep.

\section{PENDAHULUAN}

Sentralitas pengajaran iman Kristen berdasarkan Kitab Suci selalu dipahami dalam terminologi "kristosentris". Dalam pembahasannya mengenai prinsip pelayanan Inkarnasi Yesus, Febriaman Lalaziduhu Harefa (2020, p. 58) menegaskan tentang dimensi Kristosentris yakni Kristus menjadi sentral dalam segala implikasi religiusitas dalam konteks akademis maupun pada tataran pelayanan praktis. Menariknya, pembahasan mengenai pengajaran atau doktrin dalam jajaran teologi sistematika, E. Charisna Wijaya (Wijaya, 2020, p. 141) mengemukakan bahwa Kristologi merupakan doktrin yang paling banyak dibahas dan paling kontroversial sejak abad permulaan hingga masa kini yang intinya adalah berupaya menjatuhkan pengajaran kelompok ortodoks yang mendasari segala bentuk pengajaran berdasarkan Alkitab. Artikel ini hendak mengetengahkan salah satu pernyataan eksklusif yang sangat tegas dari Yesus sebagaimana terdapat dalam Yohanes 10:7 sebagai bagian integral dari pasal 10 yang dipahami sebagai sebuah perumpamaan yang khusus Craig S. Keener (2003, p. 78) mengemukakan bahwa kata; paroimian sesuai teks Yunaninya memiliki pengertian "peribahasa" yang diterjemahkan dalam teks Septuaginta (LXX), kata ini dipahami berkelindan dengan kata Ibrani lv;m'; mā̄šāl dalam teks Perjanjian Lama yang dapat dipahami dengan 3 pemaknaan secara semantik yakni proverb, parable or allegory dan riddle. Semua pengertian ini memiliki lokus yang terkait dengan pengertian kata parabolè.

Terkait dengan pemaknaan dari teks ini, D.A. Carson and R.T. France (2010, p. 1047) mengemukakan bahwa bagian ini merupakan sebuah pernyataan deklaratif oleh Yesus yang bersifat ekslusif, "the imagery now changes, with Jesus himself seen as the gate. Hal menarik lain yang dapat dipahami dalam pernyataan eksklusif di sini adalah mengenai keterbukaan Yesus mengenai diri-Nya yang semakin dikagumi saat itu oleh pengikut-Nya, meskipun tidak dapat dipungkiri bahwa kelompok yang menolaknya pun semakin merasa tersudut. Penulis memahami bahwa istilah"pintu dan gembala yang baik" dimaksudkan oleh Yesus bagi pengikut-Nya maupun bagi pendengar secara umum untuk menegaskan mengenai finalitas dan superioritas diri-Nya sebagai satu- 
satunya figur yang mampu merealisasikan keselamatan dan kehidupan kekal bagi manusia yang telah berdosa. Namun, berbagai upaya mendeklarasikan finalitas Yesus sebagaimana dipahami dalam keempat Injil kanonik maupun oleh pengikut-Nya, baik pada saat itu maupun di kemudian waktu terus ditentang oleh kelompok lain menolak finalitas-Nya. Darrell Bock \& D. B. Wallace (2009, p. 7-11) mengemukakan bahwa saat ini masih terdapat kelompok yang hanya menganggap Yesus sebatas seorang Nabi atau tokoh bijaksana dan tidak lebih dari itu.

Sesungguhnya upaya memahami dan melukiskan Yesus sebagaimana dilakukan oleh kedua kelompok, yakni yang mengakui maupun yang menolak merupakan bagian dari respons terhadap Yesus yang tentunya tidak terlepas juga dari berbagai prapaham untuk kemudian menetapkan sikap yang dapat bersifat personal maupun komunal mengenai pengakuan akan finalitas Yesus. Pemikiran inilah yang kemudian dikemukakan oleh Robert M. Bowman Jr dan J.Ed Komoszewski (2015, p. 15) bahwa setiap orang boleh saja memahami Yesus berdasarkan asumsinya dan bukan berdasarkan apa yang dikehendaki oleh Yesus sendiri sebagaimana nyata dalam kelompok Yesus Seminar atau juga sekelompok ilmuwan liberal yang radikal. Hal ini pun tergambar dalam tulisan artikel Yusuf L M (M, 2020) ketika menyoroti dua kelompok yang terus mempersoalkan eksistensi Yesus dengan proposisi Yesus sejarah dan Yesus iman.

Sejalan dengan Komoszewski, Kristolog lainnya yakni Michael Horton (2012, p. 13-14) dalam bukunya yang bertajuk Christless Christianity atau Kekristenan Tanpa Kristus melontarkan sebuah proposisi menggelitik yang lebih dalam lagi bahwa bukan hanya kelompok liberal melainkan kaum konservatif pun sedang melakukan upaya meminimalisasikan atau merendahkan Kristus dengan cara-cara yang berbeda, tentunya dengan agenda-agenda politis dan sosial yang berbeda, dengan menunjukan pengabdian mereka entah kepada budaya elit atau budaya populer. Lebih lanjut Horton mengutip George Barna dalam The Second Coming of the Church ketika mengemukakan bahwa saat ini dalam konteks kaum konservatif, penyampaian Injil ditukar dengan penegasanpenegasan dogmatik dan moralisme, dengan psikologi penolong-diri sendiri dan frasafrasa yang diulang-ulang seperti mantra untuk membuai orang.

Lontaran menggelitik oleh Horton yang mengutip pernyataan George Barna setidaknya memberikan kesan penting bahwa telah terjadi pergeseran dalam tataran 
akademis dan aktualisasi praktis yang terkait dengan penekanan mengenai sentralitas Yesus dalam kekristenan saat ini cenderung digeser dan digantikan dengan ide-ide sosial atau psikologi yang berpusat secara antroposentrisme berdasarkan filsafat humanisme. Maka kelompok yang mengakui finalitas Yesus beranggapan bahwa jika langkah menetapkan atau mempercayai finalitas Yesus didasarkan atas prinsip antroposentrisme, maka subjektifitas personal tentunya tidak dapat dihindari. Maka, konsekuensi logisnya adalah finalitas berdasarkan eksklusivitas Yesus yang ternarasi pada bagian-bagian Perjanjian Baru, termasuk juga pada Injil Yohanes 10:7 akan menjadi tidak berarti apa-apa bagi kelompok yang menolak finalitas Yesus. Pemikiran dari pengikut Yesus menganggap bahwa kaum liberal dan konservatif tidak mengikuti nasehat mereka sendiri karena sejak awal kelompok ini berkeinginan untuk menemukan sosok Yesus secara antroposentrisme yaitu hanya mengakui Yesus sebatas manusia biasa yang memperjuangkan hak-hak kesetaraan dan menolak pernyataan Yesus yang bersifat eksklusif.

Posisi pemikiran yang menolak finalitas Yesus yang dilakukan oleh sekelompok orang farisi maupun ahli taurat pada zaman Yesus terus ada hingga abad ini. hal inilah yang dideskripsikan oleh Bock dan Wallace ketika mengemukakan istilah yang cukup menggelitik dalam menyoroti argumentasinya terkait "Yesusanitas" dan "Kristianitas" yang terlihat dalam pemikiran beberapa teolog seperti Burton Mack, Elisabeth Schussler Fiorensa, yang adalah seorang ahli di Harvard. Kemudian, Bock dan Wallace \& D. B. Wallace (2009, p. 13-15) juga menyoroti pemikiran John Dominic Crossan yang dianggap sebagai salah satu tokoh paling menonjol dalam kelompok yang menggambarkan Yesus sebagai sosok petani sinis yang hanya memiliki visi sosial yang berlatar belakang Romawi-Yunani. Merujuk pada beberapa sitiran dari pemikiran para teolog maka disadari bahwa persoalan finalitas Yesus sesungguhnya belum selesai dilakukan.

Maka tujuan penelitian ini adalah bagaimana melakukan analisis teks dengan pendekatan eksegesis terhadap pernyataan Yesus yang bersifat eksklusif dengan menggunakan istilah yang perlu dipahami yaitu Gembala yang baik, Pintu dan domba sebagaimana dinarasikan dalam Injil Yohanes pasal 10:7 sebagai upaya pertanggungjawaban terhadap kelompok yang mempersoalkan finalitas Yesus sebagai 
satu-satunya Juruselamat dan tidak mungkin digeser oleh pemahaman yang bersifat antroposentrisme.

\section{METODE}

Metode yang digunakan adalah kualitatif dengan pendekatan eksegesis. Kata eksegesis berasal dari akar kata Yunani exsagō (bnd. Yoh 1:18) dengan bentuk exsēgēsato dari tempus aorist indikatif yang secara literal adalah "menuntun keluar" dalam maksud tidak memasukan gagasan, ide, pemahaman atau pemaknaan pribadi pembaca dan pendengar ke dalam sebuah teks (Cleon L. Rogers Jr \& III, 1998, p. 178). Mengomentari dua teolog yang berbeda prinsip dalam hal penyelidikan Alkitab yakni Fuller dan Erickson, Deky Hidnas Yan Nggadas (Nggadas, n.d., p. 51) mengemukakan bahwa metode eksegesis memegang peranan penting dalam hal pemahaman yang dianggap akurat dalam kaitannya dengan upaya memahami teks Alkitab secara benar

Adapun teknik pengumpulan data yang digunakan yaitu telaah pustaka. Safnil Arsyat dan Arono (2019, p. 6-7) mengemukakan bahwa telaah pustaka penting dilakukan melalui beberapa literatur yang relevan dengan pokok yang dibahas agar tidak terkesan mengulangi kembali ulasan atau sebuah konsep yang dibahas sebelumnya. Telaah pustaka juga dilakukan untuk menegaskan posisi penulis terkait dengan berbagai pandangan yang muncul mengenai sebuah pokok tertentu.

Sebagaimana diketengahkan pada kajian ini bahwa minimal terdapat tiga pandangan terkait finalitas Yesus dengan pernyataan-Nya yang bersifat eksklusif. Maka melalui telaah pustaka, penulis dapat mengeksplorasi berbagai pandangan dimaksud, yakni kelompok fundamentalis, liberalis maupun ortodoks berdasarkan eksegesis teks Yohanes pasal 10:7. Kemudian juga menegaskan posisi penulis dalam upaya pertanggungjawaban mengenai ajaran kristologi yang alkitabiah.

Langkah pertama yang dilakukan yaitu penulis melakukan observasi leksikal dan gramatika pada setiap kata dan frasa. Galang Surya Gumilang (2016, p. 154) mengemukakan bahwa observasi adalah bagian dari metode kualitatif untuk mengeksplorasi data primer guna menggali suatu makna pada sebuah teks. Kemudian, pada langkah berikutnya dilakukan observasi dan tafsiran setiap kata maupun frasa dan juga klausa yang dihubungkan dengan konteks dari pokok yang dibahas untuk mengetahui kandungan makna atas klausa dari pernyataan Yesus yang dieksegesis atau 
'ditarik keluar' berdasarkan teks Yohanes 10:7 yakni “sesungguhnya Akulah Pintu ke domba-domba itu".

\section{HASIL DAN PEMBAHASAN}

\section{Terjemahan Literal}

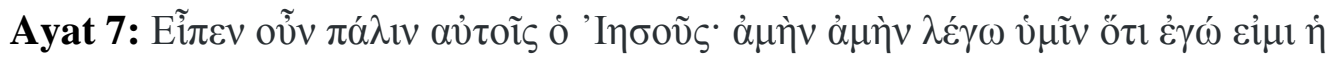

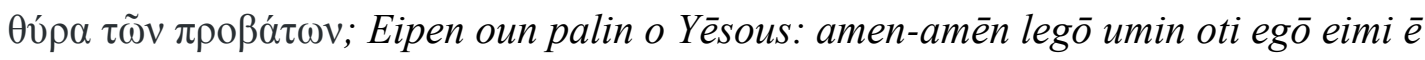
Thura tōn probaton. "Oleh sebab itu Yesus telah berkata lagi waktu itu: sesungguhsungguhnya Aku sedang mengatakan kepadamu bahwa Aku sekarang ini adalah pintu kepada domba-domba itu".

\section{Observasi Leksikal (tata kata) dan Gramatika (tata bahasa)}

Analisa leksikal dan gramatika hendak dilakukan setiap kata benda, kata, kerja, kata sifat, kata keterangan, kata ganti, kata penghubung, kata sandang, kata depan serta lainya yang terdapat dalam teks Yohanes 10:7. Penulis menganggap bahwa semua kata dalam bagian ini merupakan diksi yang penting untuk diselidiki guna "membawa keluar" kandungan makna kata (teks) sesuai dengan maksud penulis, sebagaimana

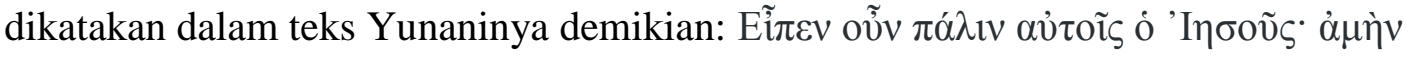

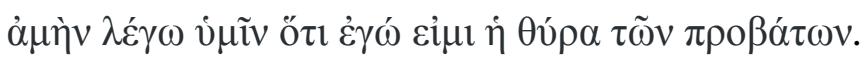

\section{Observasi dan Tafsiran: eipen oun palin o Iēsus:}

Kalimat yang terdapat pada ayat 7 diawali dengan klausa yang dalam bahasa

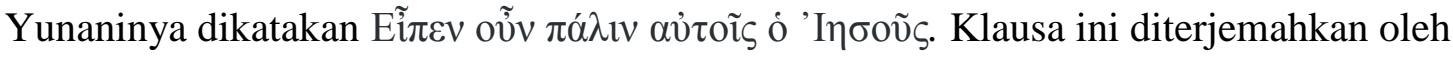
(TB-LAI) “maka kata Yesus sekali lagi”. Dalam teks Yunani, klausa ini diawali dengan kata kerja Eĩ $\pi \varepsilon v$ dan bentuk tempus indikatif aorist. Yaitu sebuah tindakan tanpa penjelasan, pencapaian dan kelangsungannya. Bentuk aktif orang ketiga tunggal dari kata dasar $\lambda \varepsilon ́ \gamma \omega$ yang dapat diterjemahkan to say, speak "dia dulunya [telah] berkata atau dia dulu [telah] mengatakan" (Scott, 1973). Hal ini berarti bahwa Yohanes sebagai pengisah cerita ini sedang mengemukakan mengenai apa yang pernah diucapkan Yesus sebelumnya kepada pendengarnya dimana Yohanes sebagai penulis pun berada sebagai pendengar. 
Kemudian, kata yang perlu dipahami juga dengan baik adalah kata ganti orang ketiga tunggal pada awal kalimat pada ayat 7 yakni "dia". Kata "dia" adalah kata ganti pribadi yang digunakan dalam Injil Yohanes, dan "dia" di sini menunjuk pada pribadi Yesus yang adalah tokoh sentral dalam teks ini. Selanjutnya terdapat partikel oưv yang berfungsi untuk menyatakan gagasan kesimpulan, maka dapat diartikan “jadi, karena itu, oleh sebab itu". Kata ỡv juga memiliki hubungan secara sintaktikal dengan kata $\pi \alpha ́ \lambda \imath v$, yaitu kata yang dapat diterjemahkan "lagi, kembali, sekali lagi, di sisi lain adalah", "the regular word for " again" is used chiefly in two senses, (a) with reference to repeated action; (b) rhetorically, in the sense of "moreover" or further". Umumnya, kata "lagi" digunakan terutama dalam dua pengertian yaitu $(a)$ dengan mengulangi keterangan dari tindakan $(b)$ secara retoris memiliki pengertian "selain itu" atau “selanjutnya lagi” (Scott, 1973). Penulis memahami bahwa maksud "sekali lagi” di sini lebih menunjuk kepada sebuah kelanjutan yang memiliki pertalian dengan subjek utama dalam pengertian orang ketiga tunggal yang menunjuk kepada Yesus dalam pengertian metafora.

Maka pembukaan kalimat sebagaimana dikemukakan oleh Yohanes didahului dengan frasa Eĩ $\pi \varepsilon v$ oũv $\pi \alpha ́ \lambda \iota v$ dapatlah dimengerti sebagai frasa pembuka bagi kalimat yang hendak diredaksikan oleh penulis dengan maksud menegaskan tentang sebuah peristiwa yang pernah terjadi pada masa sebelumnya, juga menegaskan akan subjek

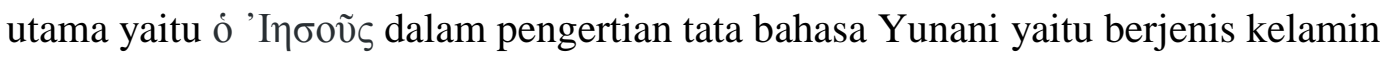
maskulin dan berkasus nominatif tunggal. Penting dipahami bahwa kata benda bentuk nominativ selalu menunjuk kepada subyek (D. B. Wallace, 2000). Selain dalam pengertian sintaktikal sebagai subyek dalam alur frasa ini, kata benda ó 'I menunjuk kepada nama personal dengan pengertian sebagai "satu-satunya Juruselamat". (Bnd. Kis. 4:12) "Dan keselamatan tidak ada di dalam siapapun juga selain di dalam Dia, sebab di bawah kolong langit ini tidak ada nama lain yang diberikan kepada manusia yang olehnya kita dapat diselamatkan” TB-LAI.

Sekali lagi, kata ó 'I bentuk transkripsi bahasa Ibrani "Joshua," yang dapat dimengerti dengan "Tuhan menyelamatkan". Nama ini digunakan oleh orang Yahudi pada zaman Yesus dengan pengertian "Anak Allah" dalam inkarnasi-Nya. Selanjutnya frasa "kata Yesus sekali

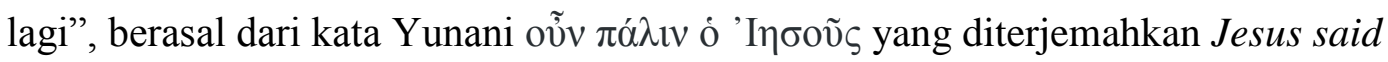


again oleh (NIV) dan "Jesus unto them again" dalam terjemahan (KJV). Namun dapat diterjemahkan juga dengan "Yesus telah mengatakan sekali lagi". Yesus menggunakan kata yang memiliki metafora dengan maksud agar dapat dipahami akan apa yang hendak disampaikan dan kemudian berdampak pada sikap percaya kepada-Nya.

Terkait dengan hal ini (Michaels, 2010) mengemukakan As Door Jesus claims to be the protector of the sheep from "the thief and robber" (v. 1b). "All who came before me are thieves and robbers," he continues, but the sheep did not hear them". Analisa pernyataan Michaels memunculkan kandungan makna leksikal menarik mengenai tujuan pengulangan Yesus di sini yang mengharapkan perhatian pada perumpamaan yang hendak Ia sampaikan dengan kata yang lebih tegas mengenai diri-Nya sebagai kunci dari "Pintu" dan sekaligus "Penjaga" bagi domba-domba agar tidak diganggu oleh pencuri dan perampok dalam pengertian secara metafora. Ridderbos mengemukakan bahwa bagian ini merupakan "respon terhadap ketidakpahaman pendengar. Maka perumpamaan itu sekarang diberikan dalam dua prikop yaitu ayat 7-10 dan ayat 11-18. Dalam perbedaan dengan apa yang Yesus lakukan dalam situasi-situasi yang terkait di Injil-Injil (bdk. Mat. 13:11 dst., 18:34; Mrk. 4:10 dst., 34), Ia memberikan penjelasan ini bukan hanya kepada murid-murid-Nya tetapi di hadapan semua orang yang mendengarnya (bdk. Ayat 19 dst.,). (Ridderbos, 2012) mengemukakan bahwa dalam prikop yang pertama fokusnya adalah mengenai Yesus sebagai Pintu, dan dalam prikop yang kedua yaitu mengenai Yesus sebagai Gembala yang baik

Bagian ini dapat dipahami bahwa tujuan Yesus menyertakan gambaran tersebut adalah untuk menyampaikan maksud penting bagi pendengarnya, baik itu murid-muridNya dan orang-orang Farisi agar dapat memahami peran-Nya sebagai "Kunci”. Karena, selain sebagai satu-satunya "Pintu”, Yesus juga adalah satu-satunya "Gembala yang baik". Thomas R. Schreiner (2015, p. 167) mengemukakan bahwa perumpamaan ini terkesan sangat berlebihan sebab seseorang tidak dapat berfungsi sebagai pintu bagi kawanan domba dan sekaligus sebagai gembala. Dengan demikian maka dapat dipahami bahwa pemikiran dari kaum libaralis dan konservatif yang cenderung menurunkan derajat Yesus secara antroposentris tidak dapat diterima karena bertentangan dengan pengajaran kristologi berdasarkan observasi dan eksegesis frasa

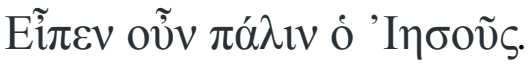


Namun penulis memahami bahwa Yohanes mengambil khotbah Yesus di sini untuk menekankan tentang sisi pelayanan dan pribadi Yesus yang unik dan lebih unggul dengan gembala dalam perspektif pendengar saat itu guna penanaman dan pembuktian spiritualitas sejati bagi pendengarnya. Martina Novalina (2020, p. 34) mengemukakan bahwa spiritualitas sejati adalah persekutuan dengan pribadi Kristus yang dikenal, yang tentunya terkait dengan sejauhmana tingkat pemahaman seseorang akan pribadi Yesus berdasarkan pengajaran-Nya.

\section{Observasi dan Tafsiran: amēn-amēn legō umin}

Kata amēn-amēn memiliki kandungan makna yang sangat erat dalam konteks Perjanjian Lama (PL) maupun Perjanjian Baru (PB). Kata ini dapat diterjemahkan dengan "sesungguhnya", dan pertama kali terdapat dalam Kitab PL yakni Ulangan 7:9 dengan pengertian kesetiaan TUHAN kepada umat-Nya yang tetap setia memegang janji-Nya turun-temurun dan melintasi zaman. Maka itu, kata amēn-amēn menjadi menarik karena dapat diterjemahkan "sesungguh-sungguhnya" dalam kaitannya dengan eksistensi Allah (Scott, 1973). Masih kata yang sama, Sutanto (Sutanto, 2004) menandaskan bahwa kata amēn digunakan dalam Alkitab PB sebanyak 129 kali Akar kata ini dapat ditelusuri hingga kaitannya dengan Emuna yang memiliki pengertian 'kesetiaan', kebenaran'. Diterjemahkan juga dengan 'begitulah hendaknya' (Yes. 65:16), 'begitulah hendaknya' dan 'Allah yang setia' (Yer. 11:5). (J.D Doglas, N Hillyer, F.F Bruce, Donald Guthrie, A.R Millard, 2011) mengemukakan bahwa dalam konteks bahasa Yunani, kata ini adalah bentuk transkripsi dari kata Ibrani yang diterjemahkan 'sungguh' dalam pengulangan rumusan. 'Sungguh-sungguh' Aku berkata kepadamu”. Maka sekali lagi, kata 'amen' juga dapat diterjemahkan dengan kandungan makna 'kepastian' yang berasal dari akar kata 'untuk menjadi teguh, tetap, dapat dipercaya';

Penulis memahami di sini bahwa Yesus memulai pernyataan-Nya dengan penegasan ini agar didengar dan dapat dipercayai mengenai hal penting yang hendak disampaikan bagi pendengar-Nya. Bahwa apa yang hendak dikatakan Yesus adalah menyangkut hal prinsip yang juga terkandung integritas-Nya. Gundry (2010) memberi komentar menarik perihal pengajaran Yesus yang menggunakan language figurative dengan maksud yang sangat penting bagi pendengar-Nya 
Namun penggunaan kata "amin" yang diterjemahkan TB-LAI "sesungguhnya" memberikan nilai tersendiri. karena "kata 'amin' sering digunakan untuk menegaskan pujian kepada Allah. Dalam (Why. 1:7; 22:20) kata itu mengungkapkan teguhnya harapan penulis dalam kehidupan. (J.D Doglas, N Hillyer, F.F Bruce, Donald Guthrie, A.R Millard, 2008) Mengemuakkan bahwa penggunaan kata itu oleh Kristus pada permulaan ucapan, sering diterjemahkan 'sesungguhnya' (mis. Yoh 3:3), adalah unik dan berarti bahwa Ia berfirman dengan kekuasaan sebagai Mesias yaitu sesuatu yang tak pernah dapat dilakukan oleh ahli-ahli Taurat maupun rabi. Itulah sebabnya dalam menggenapi, Yesus tetap memberikan janji-janji Allah yang dapat dipercayai dan pasti akan dipenuhi"

Beberapa pernyataan di atas menekankan pemahaman penting bahwa kata "sesungguhnya" adalah karena Yesus pun sangat mengetahui sikap hati dan pikiran pendengarnya yang terbagi dalam dua kelompok yaitu kelompok yang mempercayai dan kelompok yang menolak superioritas atau finalitas-Nya yang mana mereka bersama-sama sedang berada sebagai audiens dari pengajaran Yesus yang sedang berlangsung dan dipertegas secara gramatikal dengan dua kata selanjutnya yaitu legō dan umin.

Kemudian, penting sekali untuk memahami kata legō yang adalah kata kerja dengan tempus present indikatif aktif. Secara gramatikal, bentuk ini digunakan untuk peristiwa yang sedang berlangsung, dan dapat digunakan untuk membuat sebuah kisah yang dicerireakan menjadi menarik dan sesuai kenyataan. Hal ini terlihat dari ragam indikatif yang digunakan dalam tata bahasa Yunani (D. B. Wallace, 2000). Maka

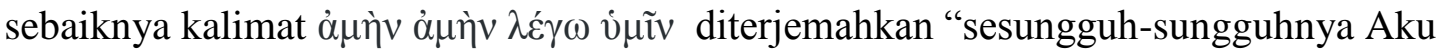
[sedang] mengatakan kepada kamu”. Maka peran dan sisi subjektifitas Yesus yang secara adalah untuk menegaskan posisi-Nya sendiri secara sungguh-sungguh (sangat serius) sebagai sentral dari pengajaran yang dilakukan bagi pendengar-Nya dengan menggunakan "alegori" yang khusus.

Proposisi "sungguh-sungguh" dalam kaitannya dengan kesetiaan Allah bagi umat terjanji yang dapat dipahami sejak dalam konteks PL menjadi sebuah realitas kekinian dalam zaman PB melalui kehadiran Yesus yang menghendaki agar eksistensi-Nya tidak perlu lagi diragukan dan dapat diterima secara logis. Hal ini berarti menolak paham fideisme yang menganggap bahwa sebuah keyakinan cukup saja menggunakan iman. 
Sebab, secara logika pun finalitas Yesus berdasarkan pernyataan-Nya dapat diterima (Gidion, 2020). Yesus tahu bahwa kelompok yang menolak-Nya akan semakin berada dalam sebuah dilema karena prinsip dan hubungan mengenai kasih Allah yang teraktualisasi dalam inkarnasi Yesus dengan karya-Nya ditekankan oleh Yesus secara terbuka dan tentunya menghendaki respons mereka dalam memberikan tanggapan atau sikap percaya atau menolak finalitas-Nya sesuai pemahaman mereka yang baik.

\section{Observasi dan Tafsiran: oti egō eimi $\bar{e}$ thura}

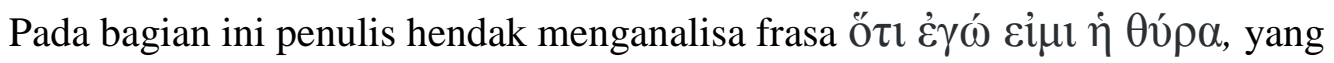
secara gramatikal dan leksikal dapat diterjemahkan "[bahwa] Akulah pintu [itu]" atau (NIV) menerjemahkan I am the gate, dan (KJV) menerjemahkannya dengan I am the door. Secara leksikal, kata ő $\tau 1$ adalah kata penghubung, conjunction subordinating nominal (Sutanto, 2004), yang dapat diterjemahkan "bahwa". Namun pada saat bersamaan, oti berfungsi juga untuk menyatakan makna kausal, maka dapatlah diterjemahkan "karena" atau "sebab". Pandensolang. Pandensolang (Pandensolang, 2009), mengemukakan bahwa kadang-kadang juga partikel ő $\tau \imath$ diterjemahkan "bahwa". Fungsi lainya yaitu menjelaskan kutipan langsung, sehingga ia tidak perlu diterjemahkan namun menyatakan gagasan seperti tanda petik dalam sebuah kalimat.

Penentuan untuk memilih terjemahan kepada kata ő $\imath$ sangat penting untuk

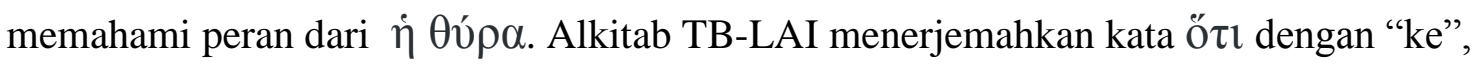
sementara Tim Penyusun Alkitab bahasa Yunani PB-LAI (LAI, 2002) menerjemahkan kata Ǒ $\tau \imath$ dengan "bagi”. Penulis memahami bahwa jikalau menerjemahkan kata ő $\tau \imath$

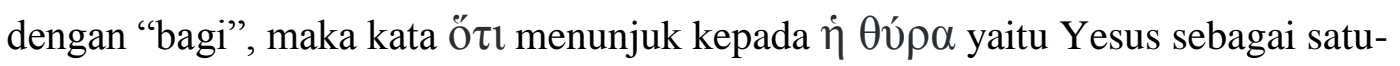
satunya sarana yang melaluinya $\tau \tilde{\omega} v \pi \rho \circ \beta \alpha ́ \tau \omega \vee$ yakni kaum pilihan dapat masuk ke dalam persekutuan bersama. Namun jikalau memilih untuk menerjemahkan kata ő $\tau \imath$ dengan "ke" (lih. TB-LAI) maka memiliki indikasi pengertian yang lain. Pengertian "ke", selain memiliki makna bahwa setiap orang juga terlibat dengan pelayanan atau penggembalaan bagi $\tau \tilde{\omega} v \pi \rho \beta \beta \alpha ́ \tau \omega \nu$, dapat juga menunjuk kepada kata $\grave{\eta} \theta \hat{\rho} \rho \alpha$ sebagai satu-satunya sarana bagi $\tau \tilde{\omega} v \pi \rho \circ \beta a ́ \tau \omega \nu$ yakni domba-domba atau kaum pilihan. "Pintu" di sini adalah menunjuk kepada Yesus yang melaluinya domba dapat 
melaluinya", Door, gate. Jesus is the door through which the sheep pass and the door through which alone men can rightly approach (Cleon L. Rogers Jr \& III, 1998). Makna metafora dari "pintu” berkaitan juga dengan manfaatnya. Sebagaimana dipahami bahwa setiap kandang domba tidak dapat menganggap bahwa "pintu" hanyalah bagian pelengkap yang dapat melengkapi bagian dari sebuah kandang domba. Sebab, keberadaan sebuah "pintu” akan menjadikan sirkulasi keluar dan masuk setiap domba.

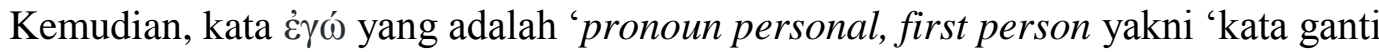
bentuk present orang pertama tunggal' yang dapat diterjemahkan "aku atau saya

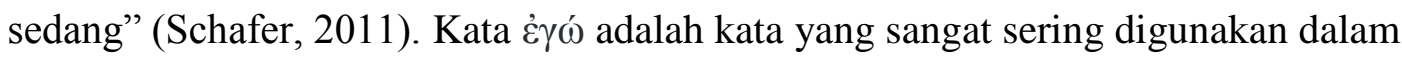

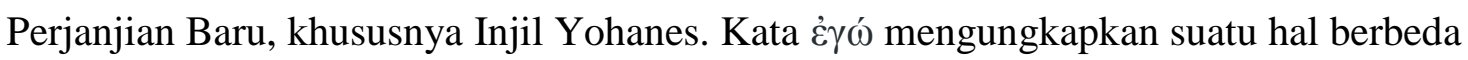

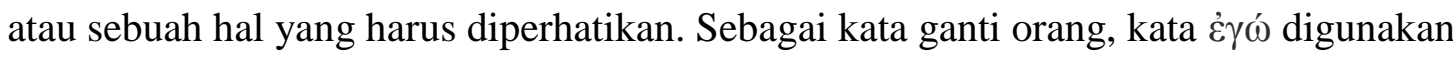
sebanyak 1.802 kali di dalam alasan dan maksud yang berbeda-beda (Schneider, 1994).

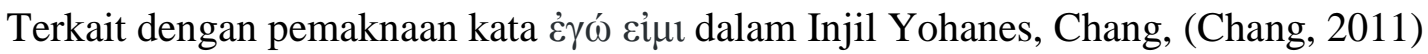
mengemukakan pemikiran yang sangat mendalam mengenai غ̇ $\gamma \omega \dot{~ y a n g ~ d a p a t ~ d i a r t i k a n ~}$ "Aku ada(lah)" sebagaimana digunakan dalam pengertian yang normal atau dalam percakapan sehari-hari, dimana Yesus berbicara sebagai seorang manusia sejati, tetapi secara khususnya sebagai "Sang Mesias".

Lebih dalam, Chang (Chang, 2011) memberikan sebuah gambaran mengenai

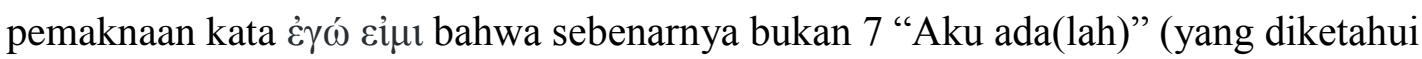
oleh kebanyakan orang Kristen), melainkan 23 kali yang merujuk kepada Yesus dengan makna khusus yang bertujuan mengarahkan setiap orang kepada pengakuan mengenai superioritas Yesus dan eksistensi-Nya. Hal ini jelas sekali oleh Yesus dalam pengajaranNya yang menuntut respons dari setiap pendengar sebagaimana ditegaskan dalam gambaran pemikiran "Aku ada(lah) (egō eimi, tenses kini) muncul 24 kali dalam Injil Yohanes, dimana 23 kalinya ada dalam kata-kata Yesus dan sekali dalam kata-kata orang buta yang disembuhkan oleh Yesus (Yoh. 9:9).

Penulis memahami bahwa Pernyataan Chang lebih cenderung menjadikan sisi teologis dan eksposisi PB secara menyeluruh dalam upaya mengetengahkan maksud “Aku ada(lah)”. Sementara Dave Hegelberg (Hagelberg, 2011) memberangkatkan pemaknaannya melalui pendekatan leksikal dan gramatikal yang lebih luas karena mencakup Perjanjian Lama untuk memberi pemahaman pada frasa $\dot{\varepsilon} \gamma \omega \dot{~ \varepsilon i ̉ \mu . ~ P e n d a p a t ~}$ lainnya, sebagaimana dikemukakan oleh Hagelberg bahwa frasa $\dot{\varepsilon} \gamma \omega \dot{~ \varepsilon i \mu t ~ t e r k a i t ~ e r a t ~}$ 
sekali dengan nama Tuhan Allah, yaitu Yahweh. Yesaya 40-55 melatarbelakangi ungkapan ini dalam Injil Yohanes. Dalam Septuaginta; misalnya dalam Yesaya 41:4;

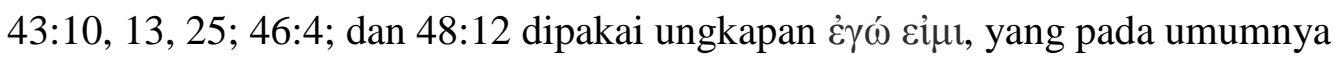
diterjemahkan “Aku tetap Dia. Dalam terjemahan baru, Yesaya 43:11-13 terkait erat dengan 3:14. Pada waktu Tuhan Allah menceriterakan nama-Nya kepada Musa dalam

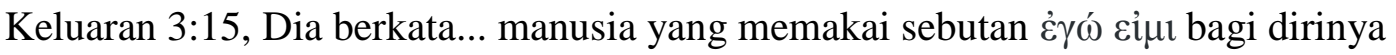
sendiri akan mengalami hukuman Allah

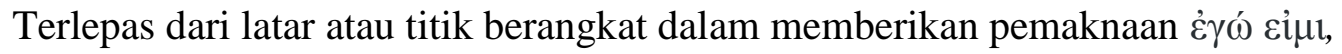
namun berdasarkan elaborasi terhadap lontaran Chang dan Hegelberg sama-sama memberikan kesan dan informasi penting mengenai pemaknaan ego eimi yang bertolak dari teks Kitab Suci dengan maksud kaharusan akan respon pendengar untuk mempercayai "Sang Ego Eimi” yang menunjuk kepada Yesus sebagai satu-satunya Juruselamat yang mampu menjaminkan keselamatan melalui diri-Nya bagi setiap orang yang percaya kepada-Nya, bnd. Yohanes 3:16.

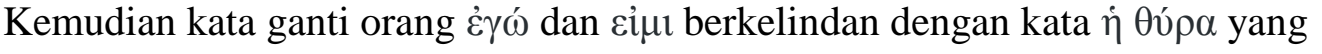
merupakan kata benda nominativ feminin tunggal (Sutanto, 2004). Kata ini digunakan sebanyak 39 kali dalam Perjanjian Baru yang beberapa pengertian yaitu: "pintu, gerbang, atau jalan masuk: (Mrk. 1:33; 2:2; 11:4; Mat. 6:6; Luk. 11:7) dari rumah; (Yoh. 10:1, 2), pintu dari kandang domba, (Yoh. 18:16; 20:19, 26; Kis. 3:2), pintu gerbang indah dari Bait Allah (Schneider, 1994). Senada dengan Schneider, (Cleon L. Rogers Jr \& III, 1998) memberikan komentar terkait dengan pengertian $\theta u ́ \rho \alpha$ yaitu' "door, gate, Jesus is the door through which the sheep pass and the door through which alone men can rightly approach the sheep".

Bentuk nominatif memiliki arti bahwa kata 'pintu' pada ayat 7 berfungsi sebagai

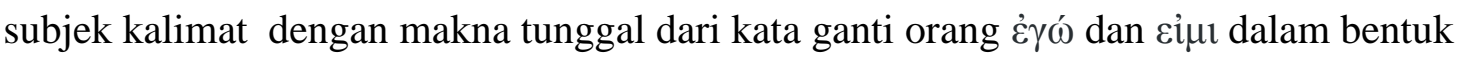
tunggal juga. Secara gramatikal, hal ini menegaskan konsistensi bentuk "tunggal” yang sama dalam penggunaan kata kerja ganti orang dengan bentuk tunggal. Itu artinya

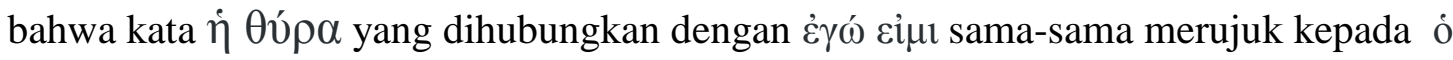
'I $\sigma o \tilde{s}$ sebagai subjek utama dalam ayat 7 yang menjadi jelas ketika memperhatikan penggunaan kata $\grave{\eta} \theta \hat{v} \rho \alpha$ dalam ayat 1 .

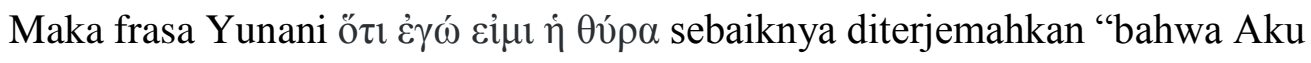
sekarang adalah satu-satunya pintu atau gerbang itu”. Schneider (Schneider, 1994) 


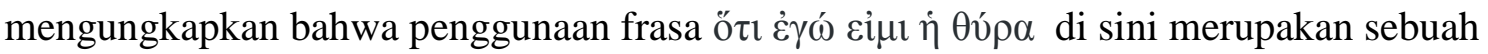
langkah Yesus yang cukup mengejutkan oleh Yesus untuk meminta perhatian yang amat serius dari pendengar-Nya".

Yesus adalah satu-satunya pintu dalam pengertian sebagai sarana untuk setiap umat terpilih (domba-domba-Nya) dapat memiliki hubungan yang istimewa. Dalam kapasitas-Nya, Yesus adalah penggenapan dari segala janji penyertaan Allah sejak zaman PL. Menarik juga karena Yesus tidak mengemukakan bahwa suatu saat Dia akan menjadi "jalan" dalam pengertian sarana menikmati kehidupan yang khusus sebagaimana dimaksud, melainkan pada saat Dia sedang mengajar, Dia juga sedang menunjukan diri-Nya sebagai jalan itu. Sekali lagi, berdasarkan observasi dan analisis teks maka terdapat lagi klaim finalitas Yesus ditekankan bagi pendengar-Nya yang tentunya relevan juga dengan berbagai pemahaman mengenai posisi Yesus yang tidak dapat disejajarkan dengan tokoh-tokoh dalam PL sebagaimana dipahami oleh orang Yahudi maupun perkembangan religiusitas dan pengajaran kristiani yang alkitabiah.

\section{Observasi dan Tafsiran: $\tau \tilde{\omega} v \pi \rho o \beta a ́ \tau \omega v$}

Berangkat dari frasa awal, maka pada bagian ini akan dideskripsikan mengenai frasa terakhir yang menunjuk kepada obyek yang menjadi sasaran kasih Allah melalui

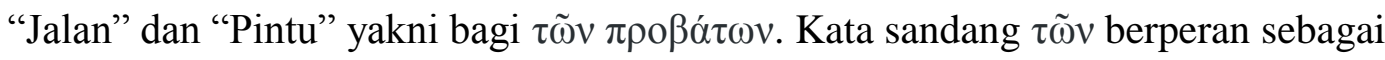
menunjuk (kata sandang) kepada sebuah kata atau term. Dan, di sini menunjuk kepada kata benda $\pi \rho \circ \beta \alpha ́ \tau \omega v$. Sebagaimana diketahui bahwa istilah ini merupakan kelanjutan

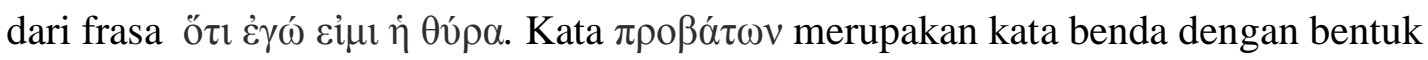
kasusnya adalah genitiv jamak yang mengarah pada kata benda $\tau \tilde{\omega} \nu \pi \rho \circ \beta \alpha ́ \tau \omega \nu$ secara jamak. Tim penerjemah (TB-LAI) menerjemahkan kata ini secara baik yaitu "dombadomba itu”. Secara harfiah, kata $\tau \tilde{\omega} v \pi \rho o \beta a ́ \tau \omega v$ yang diterjemahkan domba-domba adalah kata yang paling umum digunakan, baik dalam arti harfiah maupun kiasan. (J.D Douglas, N Hillyer, F.F Bruce, Donald Guthrie, A.R Millard, 2011) mengemukakan bahwa bahasa Ibrani ke $\underline{b} e s$ dan kese $\underline{b}$ biasanya digunakan dalam pengertian harfiah. Domba adalah jenis binatang jinak yang bersih, sudah dikenal manusia sejak zaman purba. Jenis domba yang umum dikenal di Palestina mempunyai pantat yang lebar, penuh lemak yang berharga, dan beratnya kira-kira $5 \mathrm{~kg}$ atau lebih. 
Domba adalah salah satu binatang yang selalu dikaitkan dengan orang percaya dalam konteks komunitariannya. Namun menarik, karena domba juga dikaitkan dengan diri Yesus sendiri dalam terminologi “Anak Domba Allah”. Mungkinkah kebetulan saja kalau Yesus menggunakan binatang domba sebagai gambaran mengenai orang yang mempercayai-Nya pada konteks ayat ini? Tentunya ya! Namun yang terpenting di sini adalah upaya memahami kandungan makna dari pengajaran Yesus yang menggunakan kata-kata metafora di sini diakhiri dengan istilah "domba". Tentunya, dipahami sebagai umat atau orang pilihan Allah yang menikmati keselamatan melalui karya Yesus secara devinitif. Yakni mereka yang percaya akan finalitas Yesus dan mengambil bagian dalam persekutuan umat yang menikmati janji keselamatan kekal berdasarkan karya penyelamatan yang telah dikerjakan-Nya.

\section{SIMPULAN}

Persoalan finalitas Yesus terus menjadi topik diskusi yang tidak akan berakhir. Maka solusi yang dapat diberikan melalui hasil kajian artikel ini adalah: Pertama: Yesus menyampaikan pengajaran-Nya yang amat penting ini kepada dua kelompok orang yaitu yang percaya maupun yang menolak-Nya dengan menggunakan sebuah perumpamaan khusus dan bersifat eksklusif agar membuka tabir kemisterian Allah dalam merancang keselamatan dan kehidupan kekal yang diperuntukkan bagi pendengar-Nya dan bersedia mengambil sikap percaya kepada-Nya. Yesus berkeinginan agar pendengar-Nya semakin memahami finalitas-Nya yang absolut. Kedua: Yesus menyertakan gambaran mengenai "Pintu" dengan persentase lebih dari satu kali Ia berkata, "Akulah pintu” bagi domba-domba adalah untuk memahami peran-Nya sebagai kunci. Karena selain sebagai satu-satunya "Pintu", Yesus juga adalah Gembala yang baik. Di sinilah dipahami bahwa pernyataan ekslusifitas Yesus bukan terjadi berdasarkan subjektivitas pemahaman masing-masing pendengar, melainkan berdasarkan penegasan yang keluar dari mulut Yesus sendiri. Ketiga: Hal lain yang perlu ditekankan di sini adalah eksistensi Yesus yang secara terbuka menegaskan sendiri akan posisi-Nya sebagai sentral dari pengajaran yang dilakukan dengan menggunakan "alegori" yang khusus dengan maksud memastikan "tōn probatōn" untuk dapat menikmati "keluar dan masuk" untuk terlibat melayani bersama dengan "Sang Gembala". Bahwa "Sang Gembala" sanggup untuk memilih, menetapkan, dan 
menyertai setiap domba pada segala kondisi pada setiap zaman. Keempat: Dengan

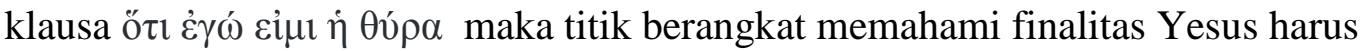
bertolak dari ucapan Yesus sendiri. Pada tataran ini juga, terdapat penghiburan penting mengenai ketersediaan "kandang domba" dalam pengertian komunitas eklesiologis yang secara sadar mengalami penyertaan-Nya yang selalu ada setiap saat yaitu dengan kalimat penghiburan-Nya yakni "sesungguh-sungguhnya Akulah Pintu ke dombadomba itu". Dengan demikian maka kontribusi penelitian ini bagi ilmu teologi, khususnya mengenai Kristologi yaitu hendak menyarankan agar sikap kritis yang didasari pada kajian alkitabiah sebaiknya terus dilakukan untuk mengimbangi kesimpangsiuran pengajaran mengenai Kristologi. Sebab, tidak dapat dipungkiri bahwa berkembangnya pemahaman yang subjektif sebagaimana halnya kaum fundamentalis atau liberalis yang terimplementasi dalam berbagai referensi yang meminimalisasi finalitas Yesus dapat menjerumuskan seseorang maupun kelompok dalam memahami eksistensi dan finalitas Yesus secara keliru, baik secara sadar maupun tanpa disadari.

\section{DAFTAR RUJUKAN}

Arono, S. A. \&. (2019). Menulis Telaah Pustaka (Literatur Review) untuk Artikel Jurnal Internasional (1st ed.). Jakarta Barat: Halaman Moeka Publishing.

Chang, E. H. H. (2011). The Only True God, Sebuah Kajian Monoteisme Alkitabiah (1st ed.). Semarang: Borobudur Publishing.

Cleon L. Rogers Jr, \&, \& III, C. L. R. (1998). The New Linguistic and Exegetical Key to the Greek New Testament (1st ed.). Michigan: Zondervan Publishing House Academic and Professional Books Grand Rapids.

France, R. T., Carson, J. A. M., \& G.J. (n.d.). dalam 21 ST-Century Edition, New Bible Commentary bersama D.A. Nottingham, England Inter-Versity Press: IVP Avademic.

Gandry, R. H. (2010). Commentary on the New Testament: Verse-byVerse Explanations with a Literal Translation (1st ed.). Peabody, Massachutts: Hendrickson Publishers Marketing, LLC.

Gidion. (2020). Kritik Terhadap Paham Fideisme dan Sekularisme Tentang Penggunaan Iman dan Pikiran. Vox Dei, Jurnal Teologi Dan Pastoral, 1, 36-

50. https://doi.org/10.46408/vxd.v1i1.16

Gumilang, G. S. (2016). Metode Penelitian Kualitatif Dalam Bidang Bimbingan Konseling. Fokus Konseling, 2, 144-159.

Hagelberg, D. (2011). Tafsiran Injil Yohanes (Pasal 6-12) (1st ed.). Yogyakarta: Penerbit Yayasan ANDI Yogyakarta.

Harefa, F. L. (2020). Menggunakan Konsep Inkarnasi Yesus sebagai Model Penginjilan Multikultural. PASCA: Jurnal Teologi Dan Pendidikan Agama 
Kristen, 16, 50-61. https://doi.org/10.46494/psc.v16i1.75

Horton, M. (n.d.). Christless Christianity: The Alternative Gospel of The American Shurch; trj. Kekristenan Tanpa Kristus (1st, trj. 2 ed.). Michigan, trj. Surabaya: Grand Rapids, MI, trj. Momentum.

J.D Doglas, N Hillyer, F.F Bruce, Donald Guthrie, A.R Millard, J. . P. \& D. . W. (Ed.). (2008). The New Bible Dictionary: Trj. Ind. Ensiklopedi Alkitab Masa Kini Jilid 1 A-L. Leicester England: Trj. Jakarta: Inter-Versity Press: Trj. Oleh: Yayasan Komunikasi Bina Kasih.

J.D Doglas, N Hillyer, F.F Bruce, Donald Guthrie, A.R Millard, J. . P. \& D. . W. (Ed.). (2011). The New Bible Dictionary: Trj. Ind. Ensiklopedi Alkitab Masa Kini Jilid 2 M-Z. Leicester England: Trj. Jakarta: Inter-Versity Press: Trj. Oleh: Yayasan Komunikasi Bina Kasih.

Keener, C. S. (2003). The Gospel of John, A Commentary Volume One, (I). Michigan.

Komoszewski, R. M. B. J. dan J. E. (2015). Patting Jesus in His Place: The Case for the Deity of Chris, tjr. Indo. Menempatkan Yesus di Takhta-Mya (1st ed.). Malang: LITERATUR SAAT MALANG.

LAI, T. P. (2002). Perjanjian Baru Indonesia Yunani (2nd ed.). Jakarta: Lembaga Alkitab Indonesia.

M, Y. L. (2020). Yesus Sejarah dan Kristus Iman. Veritas Lux Mea (Jurnal Teologi Dan Pendidikan Kristen, 2.

Michaels, J. R. (2010). The New International Commentary on the New Testamen The Gospel of John (1st ed.). Michigan: Wm. B. Eerdmans Publishing Co.

Nggadas, D. H. Y. (n.d.). Iluminasi, Eksegesis, dan Doa. BIA' Jurnal Teologi Dan Pendidikan Kristen Kontekstual, 1, no. 1, 39-55.

Novalina, M. (2020). Spiritualitas Orang Kristen Dalam Menghadirkan Kerajaan Allah di Tengah Tantangan Radikalisme. Jurnal Teologi Kontekstual Indonesia, 1, 26-33. https://doi.org/10.46445/jtki.v1i1.293

Pandensolang, W. (2009). Gramatika dan Sintaksis Bahasa Yunani Perjanjian Baru (1st ed.). Jakarta: YAI Pres.

Ridderbos, H. N. (2012). Het Evangelie naar Johannes, Proeve van een theologische Exegese; Published in English under the tittle, The Gospel according to John, Trj. Injil Yohanes: Suatu Tafsiran Teologis (1st ed.). Surabaya: Penerbit Momentum (Momentum Christian Literature).

Schafer, R. (2011). Belajar Bahasa Yunani Koine, Panduan Memahami dan Menerjemahkan Teks Perjanjian Baru (1st ed.). Jakarta: BPK Gunung Mulia.

Schneider, H. B. and G. (1994). Exsegetical Dictionary of The New Testament, Volume-1 (Aaron-Enokh) (1st ed.). Grand Rapids, Michigan: William B. Eerdmans Publishing Company.

Schreiner, T. R. (2015). New Testament Theology: Memuliakan Allah dalam Kristeus (1st ed.). Yogyakarta: ANDI Offset, Yokyakarta.

Scott, L. C. by H. G. L. and R. (1973). A Greek-English (1st ed.; R. and A. T. by S. H. S. J. with the A. of R. Mckenzie, Ed.). 
Sutanto, H. (2004). Perjanjian Baru Interlinear Yunani Indonesia dan Konkordansi Perjanjian Baru (PBIK) Jilid I (Kedua). Jakarta: Percetakan Lembaga Alkitab Indonesia.

Wallace, D. B. (2000). The Basics of New Testament Syntax An Intermediate Greek Grammar (16th ed.). Michigan: Zondervan, Grand Rapids.

Wallace, D. L. B. \& D. B. (2009). Mendongkel Yesus Dari TakhtaNya: Upaya Mutakhir untuk Menjungkirbalikan Iman Gereja Mengenai Yesus Kristus (1st ed.). Jakarta: Penerbit PT Gramedia Pustaka Utama.

Wijaya, E. C. (2020). Distorsi Teologis terhadap Inkarnasi Kristus di Dalam Teori Limitasi. PASCA: Jurnal Teologi Dan Pendidikan Agama Kristen, Volume 16, 141-151. https://doi.org/10.46494/psc.v16i2.108 